\title{
Optimization of the Hot Pressing Process for Preparing Flax Fiber/PE Thermoplastic Composite
}

\author{
Yiqi Wang ${ }^{1 *}$, Guangpeng Cui ${ }^{1}$, Zhujian Shao ${ }^{1}$, Yongjie Bao ${ }^{2}$, Hang Gao ${ }^{1}$ \\ ${ }^{1}$ Key Laboratory for Precision and Non-traditional Machining Technology of Ministry of Education, Dalian University of Technology, Dalian 116024, \\ China \\ ${ }^{2}$ Marine engineering college, Dalian Maritime University, Dalian 116026, China
}

*Corresponding Author: Yiqi Wang, Dalian University of Technology, Dalian 116024, China; wangyiqi@dlut.edu.cn

\begin{abstract}
:
The hot pressing process parameters were optimized to prepare flax fiber reinforced polyethylene (PE) thermoplastic composite by the Taguchi method. The optimal hot pressing process parameters were determined to increase the tensile strength of the composite. The optimal parameters of the design include the following sections: hot pressing temperature, pressure, hot pressing time and coupling agent modification time. An $\mathrm{L}_{9}$ $\left(3^{\star} 4\right)$ orthogonal matrix based on the Taguchi method was created. By means of analysis of signal-to-noise ratio and analysis of variance, the optimal hot pressing process parameters combination was found, compared to the average tensile strength in the nine design experiments, and the tensile strength was improved nearly $10 \%$.

Keywords: flax fiber; hot pressing process; optimization; Taguchi method; ANOVA

Citation: Y.Q. Wang, et al., Optimization of the Hot Pressing Process for Preparing Flax Fiber/PE Thermoplastic Composite. Mech Eng Sci, 2019,1(1): 42-47. https://doi.org/10.33142/me.v1i1.660
\end{abstract}

\section{Introduction}

In recent years, with global energy shortages and environmental pollution, fiber-reinforced composite materials are gradually developing towards a green ecology ${ }^{[1-10]}$. Natural fiber reinforced composites with the characteristics of low cost and recyclability are used to replace other synthesized fiber reinforced composites ${ }^{[1-3]}$. The good mechanical properties is showed by composite reinforced with natural fibers ${ }^{[5]}$. As a kind of natural fiber, flax fibers have several advantages: low density ${ }^{[6]}$, high Young's modulus ${ }^{[2]}$, biodegradability relatively high tensile and flexural modulus ${ }^{[7]}$, and it shows the same outstanding performance as glass fiber reinforced plastics ${ }^{[8-10]}$. At the same time, thermoplastic resin is superior to thermosetting compound in terms of its excellent characteristics. The thermoplastic resin is used widely as the matrix material for environmental protection. Because the polymerization reaction has been completed before the impregnation, the hot pressing process is completely a physical process, and compared with the thermosetting resin, there is no environmental pollution problem, and it is called a green material of the $21^{\text {st }}$ century ${ }^{[11]}$.

By reading a wide range of literature to study green composite or reinforced biocomposite ${ }^{[5-9]}$. With the help of hot pressing process, flax fiber and polypropylene (PP) were used as raw materials to prepare composite materials. The influence of hot pressing parameters (temperature and hot pressing time) on the mechanical properties of the composite plate was analyzed by orthogonal design. The optimal solution was obtained by the range analysis and variance analysis. It found that the mechanical properties of flax fiber/PP composite were the best with the hot pressing temperature of $180^{\circ} \mathrm{C}$ and hot pressing time of $40 \mathrm{~min}{ }^{[12]}$. When the flax fiber has a content of 30 and $40 \mathrm{wt} . \%$, the strength of the flax/PLA (polylactic acid) composite is $50 \%$ better than flax/PP composites ${ }^{[13]}$. The Flax fiber/PLA Through the analysis of peeling test and tensile test, the optimum hot pressing parameters of the flax fiber/PP composite were that pressing temperature was $180^{\circ} \mathrm{C}$, hot pressing time was $5 \mathrm{~min}$ and hot pressing pressure was $6 \mathrm{MPa}{ }^{[14]}$. For bamboo fiber/PP composite, by analysis of tensile strength and flexural strength. $170^{\circ} \mathbf{C}, 3 \mathrm{MPa}$ and 140 s are optimum hot pressing process parameters ${ }^{[15]}$. In addition, the optimum hot pressing parameters of other plant fiber composite are temperature $179^{\circ} \mathrm{C}$ and pressure 178bar ${ }^{[16]}$.

Besides the basic hot pressing parameters, in order to obtain better mechanical properties, flax fibers need to be modified during hot pressing. Coupling agents are also important 
for enhancing the mechanical properties of natural fiber thermoplastic composite. Some studies showed that the cellulose/ PP composite which the fiber modified with the maleic anhydride-polypropylene copolymer can increase the tensile strength by $80 \%{ }^{[17]}$. Mo ${ }^{[18]}$ studied the effect of ramie short fibers surface $\mathrm{KH}-550$ modification on the interlaminar fracture toughness of laminates. Besides the silane coupling agent was used to modify aramid. The contact angle test shows that the contact angle of the modified aramid becomes smaller, indicating that the KH550 silane coupling agent can be improved the hydrophilicity of aramid ${ }^{[19]}$. It found that alkali modification improved the compatibility between jute fiber and matrix, and their interface bonding strength. The mechanical properties of jute fiber reinforced composites after alkali modification are better than unmodified composite ${ }^{[20]}$. Tensile tests have been performed for evaluated the tensile strength of flax fiber reinforced composites. The Max. tensile strengths for linear low density polyethylene and its related composites reinforced by flax fibers were about 13.40MPa and the $14.30 \mathrm{MPa}{ }^{[21]}$, which were about $19.50 \mathrm{MPa}$ and the $20.50 \mathrm{MPa}$ for the cases of high density polyethylene and its related composites reinforced by flax fibers ${ }^{[22]}$

The flax fiber and PE that has low cost and can be decomposed are chosen as the raw material. Besides, the flax fiber/PE thermoplastic composite have a wide range of applications.

Many attempts have been made to study the hot pressing process of natural fiber composite materials. The most important of these is the optimal design of the pressing parameters. In addition to the traditional hot pressing parameters, fiber modification is also considered to enhance the mechanical properties of the composite plate. The selection of hot pressing parameters involves four parts: hot pressing temperature, hot pressing pressure, hot pressing time and coupling agent modification time. Reasonable adjustment of the size of the four parameters is critical to the quality of the specimen. In order to find suitable hot pressing parameters, the hot pressing experiment was carried out using the Taguchi method.

The experimental factors include four hot pressing parameters, and there are three levels in the each parameter. The $\mathrm{L}_{9}\left(3^{\star} 4\right)$ orthogonal experimental table was designed. Signal-to-noise $(\mathrm{S} / \mathrm{N})$ ratio analysis and analysis of variance (ANOVA) were carried out to determine the influence of different hot pressing parameters on the tensile strength of the specimen and the optimal experimental parameters.

\section{Experimental procedure}

\subsection{Experimental details}

As shown in Figure 1, there are flow chart of hot pressing process and material property characterization. The flax fiber and $\mathrm{PE}$ film were used as raw material to prepare fiber/PE thermoplastic composite, the hot pressing process was applied with the help of hot pressing machine to prepare composite plate. After that, the composite specimens were prepared with the size of $100 \mathrm{~mm} \times 10 \mathrm{~mm} \times 3 \mathrm{~mm}$, the tensile test was performed following by ASTM. The cross section of morphology of composite specimens were observed by SEM (scanning electron microscope).

The Taguchi method was originally established to reduce the number of experiments, and the design of experiments (DOE) were designed to find the best process parameters ${ }^{[23]}$. The DOE was realized by the matrix tool. The S/N ratio and the ANOVA are two important tools for Taguchi method analysis. They can be used to determine the optimal parameters and the influence of various experimental factors on the optimal parameters ${ }^{[24-25]}$.

The hot pressing process of the material is completed by using a hot press machine. The setting of the hot pressing parameters was designed by the Taguchi method. The mechanical properties of the specimens were tested by a universal tensile machine with a tensile rate of $1 \mathrm{~mm} / \mathrm{min}$.

The main parameters in the hot pressing process include hot pressing temperature (A), hot pressing pressure (B) and hot pressing time $(\mathrm{C})$. Because the flax fiber composite itself has poor adhesion to fibers and resins, it is necessary to modify the flax fiber with a silane coupling agent to enhance the cross-sectional bonding property. Thus, another parameter modification time (D) by silicon coupling agent is studied. As shown in the Table 1, there are four hot pressing parameters and three levels for each hot pressing parameter.

Table 1. Hot pressing process parameters and corresponding levels

\begin{tabular}{ccccc}
\hline Parameters & Unit & Level 1 & Level 2 & Level 3 \\
\hline $\begin{array}{c}\text { A (hot pressing } \\
\text { temperature) } \\
\begin{array}{c}\text { B (hot pressing } \\
\text { time) }\end{array}\end{array}$ & ${ }^{\circ} \mathrm{C}$ & 120 & 130 & 140 \\
$\begin{array}{c}\mathrm{C} \text { (pressure) } \\
\text { D (modification } \\
\text { time) }\end{array}$ & $\mathrm{MPa}$ & 1.00 & 1.50 & 2.00 \\
\hline
\end{tabular}

According to the Taguchi method, an orthogonal matrix of $\mathrm{L}_{9}\left(3^{\star} 4\right)$ was used as shown in Table 2 , it contains nine hot pressing experiments.

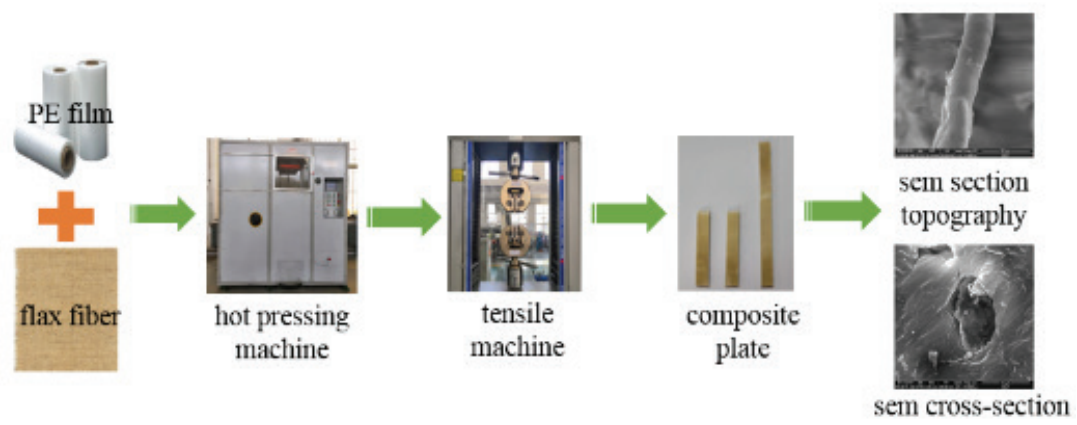

Figure 1. The flow chart of hot pressing process and material property characterization 
Table 2. An $\mathrm{L}_{9}\left(3^{\star} 4\right)$ orthogonal array of the Taguchi method

\begin{tabular}{cccccc}
\hline \multirow{2}{*}{$\begin{array}{c}\text { Number of } \\
\text { experiments }\end{array}$} & A & B & C & D & $\begin{array}{c}\text { Tensile Strength } \\
\text { /MPa }\end{array}$ \\
\cline { 2 - 6 } No. 1 & 120 & 0.25 & 1.00 & 0.50 & 23.83 \\
No. 2 & 120 & 0.50 & 1.50 & 1.00 & 23.45 \\
No. 3 & 120 & 0.75 & 2.00 & 2.00 & 26.42 \\
No. 4 & 130 & 0.25 & 1.50 & 2.00 & 24.38 \\
No. 5 & 130 & 0.50 & 2.00 & 0.50 & 25.18 \\
No. 6 & 130 & 0.75 & 1.00 & 1.00 & 22.03 \\
No. 7 & 140 & 0.25 & 2.00 & 1.00 & 25.64 \\
No. 8 & 140 & 0.50 & 1.00 & 2.00 & 22.33 \\
No.9 & 140 & 0.75 & 1.50 & 0.50 & 22.11 \\
\hline
\end{tabular}

\section{Results and discussion}

\subsection{Analysis of the $\mathrm{S} / \mathrm{N}$ ratio}

Through the $\mathrm{S} / \mathrm{N}$ ratio, the influence of each experimental factor on the response value can be analyzed and the optimal experimental parameters can be predicted. Besides, smaller-is-better (Eq. (1)), larger-is-better (Eq. (2)) and nominal-is-the best (Eq. (3)) are used to calculate the $\mathrm{S} / \mathrm{N}$ ratio.

$$
\begin{aligned}
& \eta=-10 \log \frac{1}{n}\left(\sum_{i=1}^{n} y_{i}^{2}\right) \\
& \eta=-10 \log \frac{1}{n}\left(\sum_{i=1}^{n} 1 / y_{i}^{2}\right) \\
& \eta=10 \log \frac{1}{n}\left(\sum_{i=1}^{n} y_{i}{ }^{2} / s^{2}\right)
\end{aligned}
$$

and $\eta$ is mean the $\mathrm{S} / \mathrm{N}$ ratio, $n$ represents the number of experiments, $y_{i}$ represents the response value of $i^{\text {th }}$ experiment, and $s$ is square error. In this study, tensile strength was used as an optimized response. The greater the tensile strength, the better the mechanical properties of the plate, so the second formula is chosen.

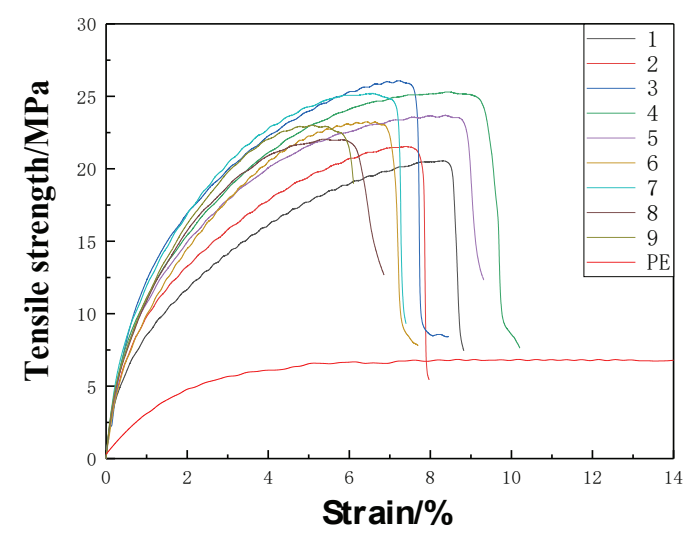

Figure 2. Stress-strain curves for flax fiber/PE composite specimens and pure resin specimens

As shown in the Figure 2, the average of the results of the three tensile specimens under each hot pressing parameter and the average of the tensile results of the pure PE resin specimens were used for comparative analysis. The flax fiber reinforced thermoplastic composite specimens has higher tensile strength than pure $\mathrm{PE}$ resin specimens, the average stress is $23.93 \mathrm{MPa}$, and the tensile strength of the pure $\mathrm{PE}$ resin specimen is $7.87 \mathrm{MPa}$. However, the pure PE resin specimens have larger strain than flax fiber/PE composite tensile specimens.

The results of the signal to noise ratio are shown in Table 3. According to Table 3, for tensile strength, the best combination of parameters: the hot pressing temperature is $120^{\circ} \mathrm{C}$, the hot pressing time is $0.25 \mathrm{~h}$, and the hot pressing pressure is $2.00 \mathrm{MPa}$, silane coupling agent modified the flax fiber for $2.00 \mathrm{~h}$.

Table 3. The $\mathrm{S} / \mathrm{N}$ response table (larger-is-better) for tensile strength

\begin{tabular}{ccccc}
\hline \multirow{2}{*}{ Level } & \multicolumn{4}{c}{ Parameters } \\
\cline { 2 - 5 } & $\mathrm{A}$ & $\mathrm{B}$ & $\mathrm{C}$ & $\mathrm{D}$ \\
\hline 1 & 27.79 & 27.82 & 27.13 & 27.49 \\
2 & 27.54 & 27.47 & 27.35 & 27.48 \\
3 & 27.35 & 27.40 & 28.21 & 27.72 \\
Delta $(\Delta)$ & 0.45 & 0.42 & 1.09 & 0.24 \\
Rank & 2 & 3 & 1 & 4 \\
\hline
\end{tabular}

\subsection{Analysis of variance (ANOVA)}

As shown in the Table 4, the ANOVA are also used to analysis the influence of each experimental factor on the response value. Besides, the percentage of contribution (P\%) of variance and $\mathrm{p}$-value are the important for the ANOVA to analyze experiment. The analysis and calculation of Taguchi experiment can refer to these two books ${ }^{[26,27]}$. The sequential sums of squares (Seq SS) and adjusted sums of squares (Adj SS) of experiment factor $k$ are given by

$$
S e q S S k=\operatorname{Adj} S S k=\sum_{i=1}^{n} 3[(m k) l-m]_{l}^{2}
$$

The formula of the adjusted mean square (Adj $M S$ ) and the F-statistic (F) are given by

$F=\frac{\operatorname{Adj} S S_{k}}{D F_{k}} \div \frac{S e q S S}{D F_{E}}$

$\operatorname{Adj} M S_{k}=\frac{\operatorname{Adj} S S_{k}}{D F_{k}}$

and $\mathrm{E}$ is mean error, $S S_{T}$ represents the total sum of squares given by

$S S_{T}=\sum_{i=1}^{n}\left(\eta_{i}-m\right)^{2}$

The formula of the percentage contribution of the different factors to the response value is given by

$P=\frac{S S_{k}}{S S_{T}} \times 100$

From the analysis of variance in Table 4, it was found that, there are differences in the magnitudes of the four $\mathrm{P}(\%)$ of $\mathrm{A}$, $\mathrm{B}, \mathrm{C}$, and $\mathrm{D}$. According to the magnitude of the $\mathrm{P}(\%)$, it can be inferred that the contribution of the four hot pressing parameters to the tensile strength is that: $\mathrm{C}>\mathrm{A}>\mathrm{B}>\mathrm{D}$. Combined with the above analysis, the optimal hot pressing process parameters are A1B1C3D3. 


\subsection{Microstructure}

As shown in the Figure 3, there are flax fiber on the section morphology of the specimens after tensile, three microscopic pictures of tensile sections with different modification times were used as controls. It can found that more matrix attached to the surface of flax fiber with the extension of the modification time with the coupling agent. Because the coupling agent modification changes the functional group on the surface of the fiber, which made the fiber and matrix have better bonding.

In addition to modification time with the coupling agent, hot pressing temperature and pressure also have a great influ- ence on microstructure, as shown in the Figure 4. No. 3 has more pressure than No. 1, and the gap between the fiber and matrix is smaller, so the combination is closer. No. 8 has a higher temperature than No. 1, and the gap between the fiber and matrix is smaller, so the combination is closer. From the above observation, it found that the PE matrix can be more easily filled into the fiber bundle in the higher hot pressing temperature and pressure. Because the higher temperature reduces the viscosity of the matrix, it has better mobility, and under the higher pressure, it is easier to immerse into the inside of the fiber bundle and reduce the internal gap of the fiber bundle.

Table 4. Summary of ANOVA results for tensile strength

\begin{tabular}{cccccccc}
\hline & DF & Seq SS & Adj SS & Adj MS & F & P (\%) & p-Value \\
\hline A & 1 & 2.1814 & 2.1814 & 2.1841 & 109.20 & 10.58 & 0.061 \\
B & 2 & 2.1485 & 2.1485 & 1.0742 & 53.71 & 10.42 & 0.096 \\
C & 2 & 15.3617 & 15.3617 & 7.6808 & 384.04 & 74.54 & 0.036 \\
D & 2 & 0.8978 & 0.8978 & 0.4489 & 22.45 & 4.36 & 0.148 \\
Error & 1 & 0.02 & 0.02 & 0.02 & & 0.10 & \\
Total & 8 & 20.6120 & 20.6120 & & & 100 & \\
\hline
\end{tabular}
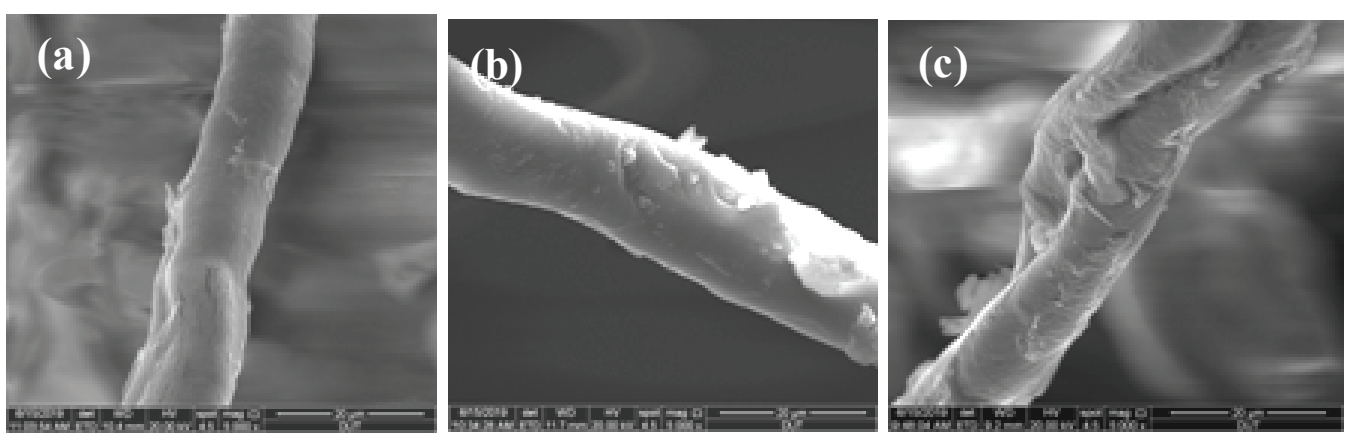

Figure 3. SEM images of flax fiber in composite (a) no modification, (b) with $0.50 \mathrm{~h}$ modification, and (c) with $2.00 \mathrm{~h}$ modification by the silane coupling agent
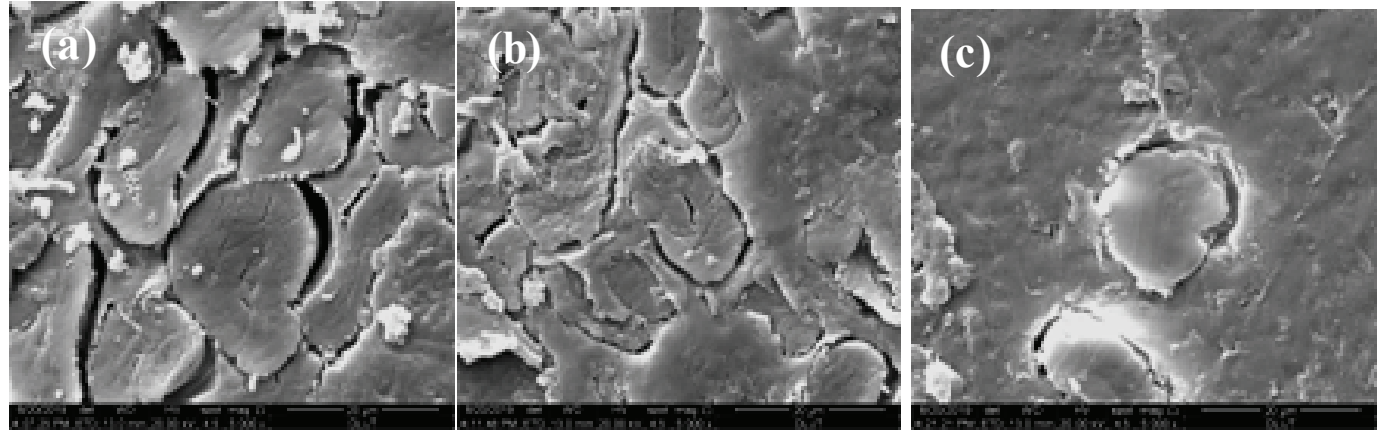

Figure 4. SEM images of composite cross section prepared at different processing conditions: (a) No. 1, (b) No. 3, and (c) No. 8

\subsection{Verification experiment}

Verification experiments are very important in engineering analysis. The optimization results can be verified by the four hot pressing parameters. The verification experiment was carried out by using the best hot pressing process A1B1C3D3. To obtain the maximum tensile strength produced by the optimization process. Base on the systematical and scientific study, the tensile strength of the flax/PE thermoplastic composite material made by other researchers were about $20 \mathrm{MPa}{ }^{[21-22]}$, and it was improved to $27 \mathrm{MPa}$, which was increased more than $30 \%$ by our optimization method. Results show that the hot pressing process parameters can be optimized effectively by the Taguchi method. It can effectively improve the tensile strength of flax fiber thermoplastic composite.

\section{Conclusion}

The Taguchi method was proposed to determine the optimal hot pressing process parameters which improved the tensile strength of the test composite specimen. In total, nine experiments were performed using an $\mathrm{L}_{9}\left(3^{*} 4\right)$ orthogonal matrix, four hot pressing parameters were chosen as design parameters, and each hot 
pressing parameter had three levels. Besides, the $\mathrm{S} / \mathrm{N}$ ratio and ANOVA were calculated for the optimization. The validation experiment was performed to verify the best parameters which can improve tensile strength. Through the analysis of the optimization of the hot pressing process, the following conclusions can be drawn:

(1) Through the analysis of the $\mathrm{S} / \mathrm{N}$ ratio, the optimal hot-pressure parameters are suggested as: the hot pressing temperature is $120^{\circ} \mathrm{C}$, the hot pressing time is $0.25 \mathrm{~h}$, and the hot pressing pressure is $2.00 \mathrm{MPa}$. The silane coupling agent modified the flax fiber for $2.00 \mathrm{~h}$. Analysis of variance results showed that, the contribution of the four factors to the tensile strength of the panel is: $\mathrm{C}>\mathrm{A}>\mathrm{B}>\mathrm{D}$, combined noise ratio analysis, the final hot pressing optimization parameter is: A1B1C3D3.

(2) The optimal hot pressing process parameter verification results show that, compared to the average tensile strength, the tensile strength under the optimal parameters is improved about $10 \%$. The Taguchi method effectively increase the tensile strength of flax fiber thermoplastic composite.

(3) Combined with hot pressing parameters and microstructure pictures, as can be seen, coupling agent modification can enhance the degree of fiber and matrix bonding, so it make the fiber surface have more matrix adhesion. The temperature and pressure work together to fill the PE matrix into the fiber bundle, high temperature reduces the viscosity of the matrix, so that it has better mobility, and under the larger pressure, it is easier to immerse into the inside of the fiber bundle. The hot pressing time has little effect on the performance of the specimen.

Acknowledgments: This work was supported by the National Natural Science Foundation of China (NSFC) [grant nos. 51605076, 51875079], and the Fundamental Research Funds for the Central Universities [grant no. DUT18LAB18].

\section{References}

[1] Witik RA, Payet J, Michaud V, et al. Assessing the life cycle costs and environmental performance of lightweight materials in automobile applications. Composite Part A: Applied Science and Manufacturing 2011; 42(11): 1700-1709.

[2] Oksman K, Skrifvars M, Selin JF, et al. Natural fibers as reinforcement in polylactic acid (PLA) composite. Composite Science and Technology 2003; 63(9): 1317-1324.

[3] Joshi SV, Drzal LT, Mohanty AK, et al. Are natural fiber composites environmentally superior to glass fiber reinforced composites? Composites Part A: Applied Science and Manufacturing. 2004; 35(3): 370-376.

[4] 4 Snoeck D, Belie ND. Mechanical and self-healing properties of cementitious composite reinforced with flax and cottonised flax, and compared with polyvinyl alcohol fibers. Biosystems Engineering 2012; 111: 325-350.

[5] Charlet K, Beakou A. Mechanical properties of interfaces within a flax bundle - Part I: Experimental analysis. International Journal of Adhesion and Adhesives 2011; 31: 875-890.

[6] Shah DU, Porter D, Vollrath F, et al. Can silk become an effective reinforcing fibers? A property comparison with flax and glass reinforced composite. Composite Science and Technology 2014; 101: 173-183.

[7] GARKHAIL SK, HEIJENRATH RWH, PEIJS T. Mechanical Properties of Natural-Fibre-Mat-Reinforced Thermoplastics based on Flax Fibres and Polypropylene. Applied Composite Materials 2000; 7: 351-372.

[8] Woigk W, Fuentes CA, Rion J, et al. Interface properties and their effect on the mechanical performance of flax fi- ber thermoplastic composite. Composite Part A: Applied Science and Manufacturing 2019; 122: 8-17.

[9] Dicker MPM, Duckworth PF, Baker AB, et al. Green composite: a review of material attributes and complementary applications. Composite Part A: Applied Science and Manufacturing 2014; 56: 280-291.

[10] Duc F, Bourban PE, Plummer CJG, et al. Damping of thermoset and thermoplastic flax fiber composite. Composite Part A: Applied Science and Manufacturing 2014; 64: 115-230.

[11] Zhang W, Huang S. Hemp fiber reinforced thermoplastic composite material and its development and application. FRP/composite 2010; 2(03): 81-83.

[12] Fu CL, Wang XL, Cui P, et al. Performance comparison of three kinds of plant fiber/polypropylene composite. Journal of Textile Science and Engineering 2018; 35(03): 110-112.

[13] Oksman K, Skrifvars M, Selin JF. Natural fibers as reinforcement in polylactic acid (PLA) composites. Composites Science and Technology 2003; 63: 1317-1324.

[14] Yang B, Wang JY, Yan BJ, et al. Preparation and Mechanical Properties Analysis of Jute Fiber/ES Fiber Composite. Shanghai Textile Technology 2017; 45(06): 26-29.

[15] Yan TH. Research on molding process and properties of flax thermoplastic reinforced composite. Shanghai: Dong hua University, 2009. 50-86.

[16] Liu TS. Research on Dry Hot Pressing Process Optimization and Molding Equipment for Plant Fiber Tableware. China Academy of Agricultural Mechanization Sciences 2009; 40: 200-218.

[17] Arbelaiz A, Ferna'ndez B, Ramos JA, et al. Mechanical properties of short flax fibre bundle/polypropylene composites: Influence of matrix/fibre modification, fibre content, water uptake and recycling. Composites Science and Technology 2005; 65: 1582-1592.

[18] Mo ZC, Hu CY, Guo CC, et al. Intercalation of ramie short fiber between carbon fiber/epoxy matrix composite. Journal of Composite Materials 2017; 34(06): 12371244.

[19] Wang YJ, Meng JG, Zhang YF, et al. Performance Test of Aramid Modified by Silane Coupling Agent. Synthetic fiber 2017; 46(04): 43-46.

[20] Ma W. Preparation and properties of thermoplastic natural bamboo fiber composite. Hangzhou: Zhejiang Agriculture and Forestry University, 2012. 47-68.

[21] Li X, Panigrahi S, Tabil LG. A study on flax fiber reinforced polyethylene biocomposites. Applied Engineering in Agriculture 2009; 25(4): 525-531.

[22] $\mathrm{Ku} \mathrm{H}$, Wang $\mathrm{H}$, Pattarachaiyakoop N, et al. A review on the tensile properties of natural fiber reinforced polymer composites. Composites: Part B 2011; 42: 856-873.

[23] Wang YQ, Afsar AM, Song JI. Optimization of brazing conditions for OFHC Cu and ASTM A501 low carbon steel by Taguchi method. International Journal of Precision Engineering and Manufacturing 2009; 10: 97-104.

[24] Wang YQ, Byun JH, Kim BS, et al. The use of Taguchi optimization in determining optimum electrophoretic conditions for the deposition of carbon nanofiber on carbon fibers for use in carbon/epoxy composite. Carbon 2012; 50: 2853-2859.

[25] Taguchi G. Introduction to quality engineering. New York: McGraw-Hill; 1990.

[26] Roberts MJ, Russo R. A student's guide to analysis of variance. London: Routledge, 2009. 92-109.

[27] Montgomery DC. Design and analysis of experiments $\left(5^{\text {th }}\right.$ ed.). New York: John Wiley Sons, 2001. 65-72. 